Int. J. Electrochem. Sci., 15 (2020) 9120 - 9134

\title{
Corrosion Properties of Pure Aluminum Prepared by Spark Plasma Sintering (SPS) Using Different Grain Size of Aluminium Powders as Raw Material
}

\author{
Wenming Tian ${ }^{1}$, Fangfang Chen ${ }^{1, *}$, Fasong Cheng ${ }^{2}$, Zhonglei Li ${ }^{1}$, Guoxing Pang ${ }^{1}$ \\ ${ }^{1}$ School of Materials Engineering, North China Institute of Aerospace Engineering, No.133 \\ Aimindong Road, Langfang Hebei Province 065000, China. \\ ${ }^{2}$ AECC Guizhou Liyang Aviation Power CO.,LTD. Guiyang Guizhou 550014, China \\ "E-mail: $\underline{605917370 @ q q . c o m}$; tianwenming.dhr@163.com
}

doi: $10.20964 / 2020.09 .02$

Received: 17 April 2020 / Accepted: 5 June 2020 / Published: 10 August 2020

Five kinds of pure aluminum were prepared by spark plasma sintering using different grain size of aluminum powders as raw material. The effect of grain size on corrosion and passivation properties of these kinds of aluminum was investigated by potentiodynamic polarization, electrochemical impedance spectroscopy (EIS), Mott-Schottky test and immersion test. The results revealed that fine grain aluminum showed a bigger passive current density than those containing coarse grains. The corrosion current density at OCP also increased with decreasing grain size, indicating that the passive film formed on fine grains had a faster dissolution and repair rate. The pitting potential and the width of passive range increased with decreasing grain size. While, the defect density in passive film decreased with increasing grain size. The passive film formed on aluminum containing fine grains had superior protection performance against localized corrosion in general.

Keywords: A. Aluminum; B. Potentiodynamic; B. EIS; B. Mott-Schottky; B. Immersion test; C. Passive film

\section{FULL TEXT}

(C) 2020 The Authors. Published by ESG (www.electrochemsci.org). This article is an open access article distributed under the terms and conditions of the Creative Commons Attribution license (http://creativecommons.org/licenses/by/4.0/). 